\title{
STUDY OF THE KIDNEY IN THE BANTU WITH HYPERTENSION
}

\author{
BY \\ CHARLES ISAACSON AND PRISCILLA KINCAID-SMITH \\ From the South African Institute for Medical Research and Baragwanath Hospital, Johannesburg, and \\ the Department of Medicine, University of Melbourne, Australia \\ Received November 7, 1961
}

\begin{abstract}
Hypertension is common in the Bantu of Southern Africa (Becker, 1946; Ordman, 1948; Schrire, 1958). Schrire (1958) found that diastolic pressures were higher and electrocardiographic changes of left ventricular hypertrophy greater in the Bantu than in whites, and that hypertension occurs at an earlier age in the non-white races. There has been some difference of opinion about the renal pathology in Bantu subjects with hypertension. Levin (1957) stated that in 398 consecutive necropsies in Bantus 54 showed evidence of hypertension of which $34(63 \%)$ were essential and $18(33 \%)$ were secondary to chronic pyelonephritis. Uys on the other hand, while claiming that 48 per cent of those with hypertension in his autopsy series had underlying renal disease nevertheless found that only 12 per cent showed pyelonephritis, whereas 29 per cent showed glomerulonephritis.

This paper presents the morbid anatomical and histopathological findings in the kidneys of a series of Bantu subjects with severe hypertension.
\end{abstract}

\section{Materials AND MethodS}

The findings in 1232 consecutive autopsies (751 men, 481 women) performed over a period of three and a quarter years on patients over the age of 20 years who had died of natural causes have been reviewed. Those patients with a blood pressure of $200 / 100 \mathrm{~mm}$. $\mathrm{Hg}$ or more who died of hypertensive disease, such as heart failure, uræmia, or cerebral hæmorrhage, were selected for study. Using these criteria it is clear that a number of hypertensive subjects may have been excluded. On the other hand it is unlikely that non-hypertensive subjects with a terminal transient rise in blood pressure would be included. Fifty-eight cases were chosen. Histological sections were stained with hæmatoxylin and eosin, periodic-acid Schiff, elastic van-Gieson, and phosphotungstic acid-hæmatoxylin.

\section{RESULTS}

The age and sex distribution of the 58 cases is shown in Table I. A striking feature is the comparatively young age of the patients; 33 subjects $(57 \%)$ were between 30 and 49 years of age. This is probably in part a reflection of the criteria used in selecting the cases. Young patients with a blood pressure of $200 / 100$ or more are more likely to die of their disease than are older patients. The 26 men comprised 3.6 per cent of all autopsies on men and the 32 women comprised 6.7 per cent of the autopsies on women.

The histological findings in the kidneys are shown in Table II. Thirty-seven cases $(64 \%)$ showed the features of essential nephrosclerosis and of these $28(48 \%)$ had malignant changes, namely fibrinoid necrosis in afferent arterioles and cellular intimal proliferation in interlobular arteries. Twenty-one cases $(36 \%)$, including three cases of toxæmia of pregnancy, had underlying renal disease, and of these only $6(10 \%)$ showed the changes of chronic pyelonephritis. 
TABLE I

Age and Sex Distribution of 58 Bantus with Hypertension

\begin{tabular}{c|c|c}
\hline Age in years & Men & Women \\
\hline $20-29$ & 3 & 3 \\
$30-39$ & 7 & 11 \\
$40-49$ & 8 & 7 \\
$50-59$ & 4 & 7 \\
$60-69$ & 3 & 3 \\
70 or over & 1 & 1 \\
\cline { 2 - 3 } & 26 & 32 \\
\hline
\end{tabular}

TABLE II

The Renal Histological Changes in 58 Bantus with Hypertension

\begin{tabular}{|c|c|c|c|}
\hline \multicolumn{2}{|c|}{ Histological diagnosis } & Number of cases & Percentage \\
\hline \multirow{2}{*}{\multicolumn{2}{|c|}{ 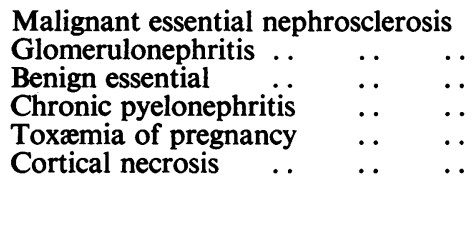 }} & $\begin{array}{r}28 \\
11 \\
9 \\
6 \\
3 \\
1\end{array}$ & \multirow[t]{2}{*}{$\begin{array}{r}48 \\
19 \\
16 \\
10 \\
5 \\
2\end{array}$} \\
\hline & & 58 & \\
\hline
\end{tabular}

Forty-five of the 58 cases showed the changes of malignant hypertension defined above. The renal findings in this group with malignant hypertension are shown in Table III. The majority $(64 \%)$ showed the features of malignant nephrosclerosis alone. In only 16 subjects $(36 \%)$ was there evidence of underlying renal disease and only $4(9 \%)$ of these showed chronic pyelonephritis.

TABLE III

Malignant Hypertension. Comparison of the Renal Findings Post Mortem in 45 Bantus and 124 Britons

\begin{tabular}{|c|c|c|c|c|}
\hline \multirow[t]{2}{*}{ Diagnosis } & \multicolumn{2}{|c|}{45 Bantus } & \multicolumn{2}{|c|}{124 Britons } \\
\hline & No. of cases & Percentage & No. of cases & Percentage \\
\hline $\begin{array}{l}\text { Essential hypertension } \\
\text { Glomerulonephritis } \\
\text { Chronic pyelonephritis } \\
\text { Toxæmia of pregnancy } \\
\text { Cortical necrosis } \\
\text { Miscellaneous }\end{array}$ & $\begin{array}{r}29 \\
10 \\
4 \\
1 \\
1 \\
0 \\
45\end{array}$ & $\begin{array}{r}64 \\
22 \\
9 \\
2 \\
2 \\
-\end{array}$ & $\begin{array}{r}52 \\
18 \\
26 \\
3 \\
0 \\
25 \\
124\end{array}$ & $\begin{array}{l}42 \\
15 \\
21 \\
2 \cdot 4 \\
\frac{19}{19}\end{array}$ \\
\hline
\end{tabular}

\section{Discussion}

The findings in this study support the views of most observers with regard to the high frequency of severe hypertension in the Bantu. The main object of the survey was to determine the importance of underlying renal disease in this group of severely hypertensive subjects. In two-thirds of the cases $(64 \%)$ there was no underlying renal disease and the kidneys merely showed the effects of the hypertension. Only 10 per cent of cases showed the lesions of chronic pyelonephritis. Fraser 
(1959) obtained autopsy evidence in 47 out of 264 hypertensive Bantu subjects; twenty-one (45\%) had underlying renal disease which in $15(32 \%)$ was due to pyelonephritis. Thus chronic pyelonephritis was three times as common in his series as in ours although other forms of renal disease were decidedly less frequent in his group. Because Fraser took less severely hypertensive subjects with a blood pressure of $140 / 90$ or over, one might expect a lower incidence of underlying renal disease, and the high incidence of pyelonephritis in his series is therefore surprising. Becker (1946) found that 61 per cent of hypertensive subjects revealed no underlying renal diseases post mortem, and this figure is similar to ours.

In a clinical series of 197 cases of malignant hypertension reported from London (Kincaid-Smith et al., 1958) the kidneys were studied histologically in $124(62 \%)$. Essential hypertension was found in 42 per cent of cases, chronic pyelonephritis in 21 per cent, and chronic glomerulonephritis in 15 per cent. Using the same criteria for diagnosis in the present series the cases with malignant hypertension showed a far lower incidence of underlying chronic pyelonephritis (Table III).

It is clear therefore that essential hypertension is the final pathological diagnosis in the majority of cases of severe hypertension in the Bantu and that renal disease plays an even less important role than it appears to do in Britain. The claim of Levin (1957) and Fraser (1959) that the frequency of hypertension in the Bantu is due to a high incidence of underlying renal disease is not borne out by our findings; nor do our results agree with reports from Uganda that under the age of 40 years some 85 per cent of cases of hypertension seen in hospital are of renal origin, and that over the age of 40 years renal hypertension remains extremely common (Somers, 1959; Shaper and Williams, 1960).

\section{SUMMARY}

In a necropsy study of the renal lesions in severe hypertension in Bantus, essential nephrosclerosis was found in 64 per cent, glomerulonephritis in 19 per cent, and pyelonephritis in only 10 per cent. Renal disease seems to be less frequent as an underlying cause of severe hypertension in Bantus than in subjects in Britain.

We should like to thank the Director of the South African Institute for Medical Research for granting us facilities, and the Superintendent of Baragwanath Hospital for permission to publish our findings.

\section{REFERENCES}

Becker, B. J. P. (1946). S. Afr. J. med. Sci., 11, 107.

Fraser, B. N. (1959). Brit. med. J., 1, 761.

Kincaid-Smith, P., McMichael, J., and Murphy, E. A. (1958). Quart. J. Med., $27,117$.

Levin, N. W. (1957). Leech (Johannesburg), 27, 29.

Ordman, B. (1948). Clin. Proc., 7, 183.

Shaper, A. G., and Williams, A. W. (1960). Trans. Roy. Soc. Trop. Med., 54, 12.

Shrire, V. (1958). Amer. Heart J., 56, 742.

Somers, K. (1959). S. Afr. med. J., 33, 515.

Uys, C. J. (1953). Renal Disease in the Bantu. M.D. thesis, University of the Witwatersrand. 